\title{
A study on ranking ethical factors influencing customer loyalty
}

\author{
Ebrahim Abedini ${ }^{a^{*}}$, Abdollah Naami ${ }^{b}$ and Mahmood Modirib
}

${ }^{a}$ Department of Management, Islamic Azad University, South Tehran Branch, Tehran, Iran

${ }^{b}$ Assistant Professor, Department of Management, Islamic Azad University, South Branch, Tehran, Iran

\section{CHR ON I C L E}

\section{Article history:}

Received May 20, 2013

Received in revised format

12 August 2013

Accepted 7 September 2013

Available online

September 102013

Keywords:

Customer loyalty

VIKOR

$A N P$

Ethical values

\section{A B S T R A C T}

Having loyal customer is the primary objective of any business owner since loyal customers purchase on regular basis, create sustainable growth and reduce risk of bankruptcy. During the past few years, many people argue that customer loyalty must be established through ethical values. In this paper, we present an empirical investigation to detect ethical factors influencing customer loyalty. The proposed study determines five criteria including customer repurchase, interest in brand, recommending brand to others, positive attitude toward brand and cognitive loyalty to brand. These criteria have been ranked using fuzzy analytical network process. The study determines 14 different ethical values, which may play essential role on customer loyalty and using VIKOR, different ethical values are ranked. The study indicates that welcoming customers is the most important factor followed by cheerfulness, on time delivery, being informative and having appropriate standards.

\section{Introduction}

Customer loyalty plays essential role on the success of business owners and it is the primary source of building successful business models. There are different methods to create loyal customers where some are ethical and some are not. Ethical values, on the other hand, are becoming essential requirements for having well known business units. Ethical values include various factors including welcoming customers, having cheerfulness employees, on time delivery, being informative, etc. and there is a growing interest in detecting important factors influencing customer loyalty. There are normally various criteria and some of them may be in conflict. Therefore, we need to use multi criteria decision making (MCDM) techniques to find influential factors and to rank them, properly. Analytical network process (ANP) is one of the most popular MCDM methods for ranking different alternatives. The technique is an extension of analytical hierarchy process where inter-relationships among various alternatives are also taken into account (Saaty, 1996, 2004; Ware et al., 2012).

\footnotetext{
*Corresponding author. Tel: +989127517996

E-mail address: eabedini@rihu.ac.ir (E. Abedini) 
Yadollahi Farsi et al. (2012) introduced a technique of fuzzy decision making for ranking various alternatives by using recent advances in ranking methods for product selection. The proposed study applied oral preferences language stated in terms of triangular and trapezoid fuzzy numbers. Then, a multi criteria hierarchical decision making is recommended on the basis of fuzzy collection theory for product selection where the proposed fuzzy VIKOR implemented various qualitative and quantitative criteria.

\section{The proposed method}

Many MCDM methods do not deal with the interdependences among elements and to handle such problem, ANP as a new MCDM technique was developed by Saaty (1996). Saaty (1999) has demonstrated various types of ANP techniques, such as the Hamburger Model, the Car Purchase BCR model, and the National Missile Defense model. The proposed model of this paper recommends a modified Feedback System model (Fig. 1) that permits inner dependences within the criteria cluster, in which the looped are signifies the inner dependences.

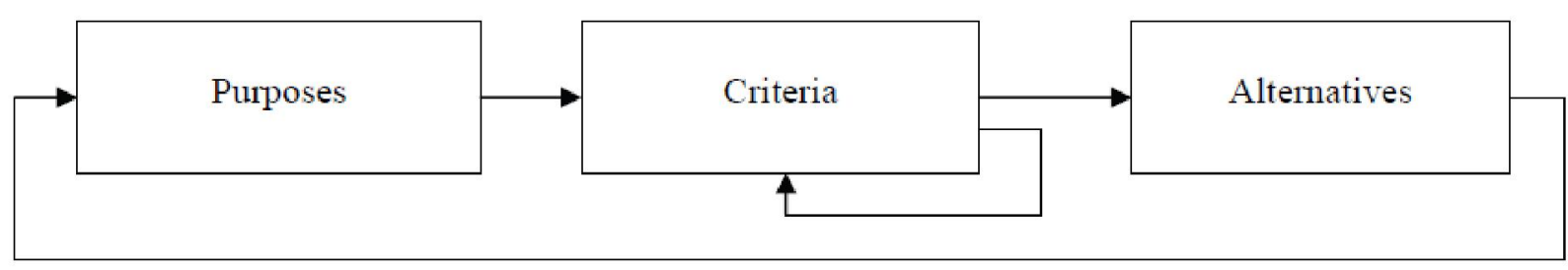

Fig.1. Feedback system model

To compute the relative importance among elements, all decision makers are requested to depend on a series of pair-wise comparisons. These pair-wise comparisons are based on the Saaty's nine-point scale 1-9 and to evaluate the weights of elements, the AHP uses the principal eigenvector of comparison matrix, whereas the ANP implements the limiting process method of the powers of the super-matrix (Sekitani \& Takahashi, 2001). When we ask decision maker to express his/her opinions, there are normally some uncertainties associated with his/her insights. Therefore, we could use fuzzy numbers to handle uncertainty.

Afsharkazemi et al. (2012), for instance, applied Fuzzy ANP in an application of quality function deployment (QFD) for ranking different options. They applied fuzzy matrix and house of quality to investigate the products development in QFD. Alvandi et al. (2012) proposed an integrated MCDM technique for ranking BSC perspectives and key performance indicators (KPIs) applying a hybrid of decision making trial and evaluation laboratory (DEMATEL) and (ANP) techniques. Fazli and Jafari (2012) applied a hybrid of ANP and DEMATEL methods for investment purposes. Serkani et al. (2013) used a hybrid of AHP and ANP methods for choosing improvement projects of Iranian Excellence Model in healthcare sector. Lin and Tsai (2009) presented an expert selection system to choose ideal cities for medical service ventures. They presented an effective technique based on the ANP combined with the method for order preference by similarity to ideal solution (TOPSIS) to assist medical service inventors who looked for assessing proper city.

The proposed model of this paper uses ANP to rank different factors influencing customer loyalty. The study performed a brain storming survey and detected 14 important factors influencing customer loyalty. In performing pairwise comparison, the study uses triangular numbers to handle any uncertainties. Next, we use Fuzzy Vlse Kriterijumska Optimizacija Kompromisno Resenje (VIKOR) to rank various ethical alternatives for improving customer loyalty. 
VIKOR method was introduced by Opricovic (1997) and Trajkovic et al. (1997) to handle multi attribute decision making (MADM) problems. This method concentrates on prioritizing the best alternative from a set of alternatives (Opricovic \& Tzeng 2004; Tzeng 2004; Opricovic, 2008). VIKOR method calculates ratio of positive and negative ideal solutions to propose a compromise solution with an advantage rate (Tzeng et al., 2005; Chu et al., 2007). The procedure of fuzzy VIKOR consists of the following steps (Chen \& Wang, 2008):

Step 1: Determine feasible alternatives, determine the evaluation criteria, and set up a group of decision makers. Let $m$ represent alternatives, $k$ evaluation criteria, and $n$ decision makers.

Step 2: Determine linguistic variables and their corresponding triangular fuzzy numbers. Linguistic variables are applied to evaluate the relative importance of the criteria and the rate alternatives with respect to different criteria.

Let $\tilde{A}$ and $\tilde{B}$ be two triangular fuzzy numbers (TFN) denoted by the triple $\left(a_{1}, a_{2}, a_{3}\right)$ and $\left(b_{1}, b_{2}, b_{3}\right)$, respectively the operational laws of these two triangular fuzzy numbers are represented in Table 1 and Table 2 as follows:

\section{Table 1}

Linguistic terms for the importance weights along with their relative importance

\begin{tabular}{lllllll}
\hline Very low(VL) & Low $(\mathrm{L})$ & Medium low $(\mathrm{ML})$ & Medium $(\mathrm{M})$ & Medium high $(\mathrm{MH})$ & High $(\mathrm{H})$ & Very high $(\mathrm{VH})$ \\
\hline$(0,0,0.1)$ & $(0,0.1, .3)$ & $(0.1,0.3,0,5)$ & $(0.3,0.5,0.7)$ & $(0.5,0.7,0.9)$ & $(0.7,0.9,1)$ & $(0.9,1,1)$ \\
\hline
\end{tabular}

Table 2

Linguistic terms for the importance rating along with their relative importance

\begin{tabular}{lllllll}
\hline Very bad(VB) & Bad (B) & Medium bad (MB) & Medium (M) & Medium good (MG) & Good (G) & Very good (VG) \\
\hline$(0,0,1)$ & $(0,1,3)$ & $(1,3,5)$ & $(3,5,7)$ & $(5,7,9)$ & $(7,9,10)$ & $(9,10,10)$ \\
\hline
\end{tabular}

Step 3: Integrate decision makers' preferences and insights. The decision is extracted by aggregating the fuzzy weight of criteria and fuzzy rating of alternatives from $n$ decision-maker calculated as follows,

$$
\tilde{w}_{j}=\frac{1}{n}\left[\sum_{e=1}^{n} \tilde{w}_{j}^{e}\right], j=1,2, \ldots, k
$$

The preferences and opinions of $n$ decision-maker with respect to $j^{\text {th }}$ criterion for the relative importance weight of each criterion and the rating of each alternative in the $i^{\text {th }}$ alternative can be measured as follows,

$$
\tilde{x}_{i j}=\frac{1}{n}\left[\sum_{e=1}^{n} \tilde{x}_{i j}^{e}\right], i=1,2, \ldots, m \quad \tilde{W}=\left[\tilde{w}_{1}, \tilde{w}_{2}, \ldots, \tilde{w}_{k}\right]
$$

Step 4: Compute fuzzy weighted average and construct the normalized fuzzy decision matrix:

$$
\begin{aligned}
& \begin{array}{lllll}
C_{1} & C_{2} & \mathrm{C}_{3} & \cdots & C_{k}
\end{array}
\end{aligned}
$$

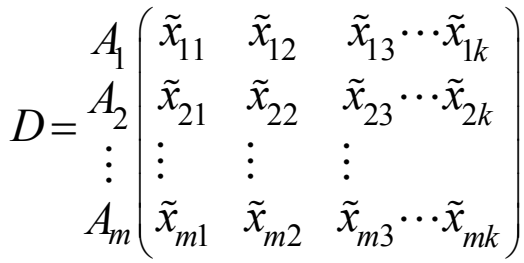


where $X_{\mathrm{ij}}$ is the relative rating of alternative $A_{\mathrm{i}}$ with respect to criterion $C_{\mathrm{j}}$, and $W_{\mathrm{j}}$ is the relative importance of the $j^{\text {th }}$ criterion. This study, therefore, uses two linguistic variables $X_{\mathrm{ij}}$ and $W_{\mathrm{j}}$ as triangular fuzzy numbers.

Step 5: Determine the fuzzy best value (FBV) and fuzzy worst value

$$
\tilde{f}_{j}^{*}=\max _{i} \tilde{x}_{i j}, \tilde{f}_{j}^{-}=\min _{i} \tilde{x}_{i j}
$$

Step 6: Calculate the values:

$$
\frac{\tilde{w}_{j}\left(\tilde{f}_{j}^{*}-\tilde{x}_{i j}\right)}{\left(\tilde{f}_{j}^{*}-\tilde{f}_{j}^{-}\right)}, \quad \tilde{S}_{i}=\sum_{i=1}^{k} \frac{\tilde{w}_{j}\left(\tilde{f}_{j}^{*}-\tilde{x}_{i j}\right)}{\left(\tilde{f}_{j}^{*}-\tilde{f}_{j}^{-}\right)}, \tilde{R}_{i}=\max _{j}\left[\frac{\tilde{w}_{j}\left(\tilde{f}_{j}^{*}-\tilde{x}_{i j}\right)}{\left(\tilde{f}_{j}^{*}-\tilde{f}_{j}^{-}\right)}\right] \text {, }
$$

where $\tilde{S}_{i}$ and $\tilde{R}_{i}$ denote the utility as well as the regret measure, respectively, and $W_{j}$ is the weight of the $j^{\text {th }}$ criterion.

Step 7: Calculate the values of $\widetilde{S}^{*} ; \tilde{S}^{-} ; \tilde{R}^{*} ; \tilde{R}^{-} ; \tilde{Q}_{i}$ :

$$
\begin{aligned}
& \tilde{S}^{*}=\min _{i} \tilde{S}_{i}, \tilde{S}^{-}=\max _{i} \tilde{S}_{i} \\
& \tilde{R}^{*}=\min _{i} \tilde{R}_{i}, \tilde{R}^{-}=\max _{i} \tilde{R}_{i} \\
& \tilde{Q}_{i}=v \frac{\left(\tilde{S}_{j}-\tilde{S}^{*}\right)}{\left(\tilde{S}^{-}-\tilde{S}^{*}\right)}+(1-v) \frac{\left(\tilde{R}_{j}-\tilde{R}^{*}\right)}{\left(\tilde{R}^{-}-\tilde{R}^{*}\right)}
\end{aligned}
$$

Here, $\tilde{S}^{*}$ represents the minimum value of $\tilde{S}_{i}$, which is the maximum majority rule or maximum group utility, and $\tilde{R}^{*}$ is the minimum value of $\tilde{R}_{i}$, which is the minimum individual regret of the opponent. Thus, the index $\tilde{Q}_{i}$ is computed and is based on the consideration of both the group utility and individual regret of the opponent. In addition, $v$ here means the weight of the strategy of the maximum group utility (Wu et al., 2009). For more details of the implementation of this method, interested readers are referred to Yadollahi Farsi et al. (2012).

\section{The results}

In this section, we present details of our survey on measuring the relative importance of each criteria based on the implementation of FANP and VIKOR. We first present details of ranking four major criteria in Table 3 as follows,

\section{Table 3}

The summary of ranking five main criteria using FANP

\begin{tabular}{lc}
\hline Item & Weight \\
\hline Customer repurchase & $(0.24,0.61,0.95)$ \\
Interest in brand & $(0.48,0.72,0.97)$ \\
Recommend to others & $(0.16,0.29,0.49)$ \\
Positive attitude towards brand & $(0.24,0.68,0.37)$ \\
Cognitive loyalty to brand & $(0.16,0.22,0.30)$ \\
\hline
\end{tabular}

As we can observe from the results of Table 3, interest in brand is the most important factor followed by customer repurchase, recommend to others, positive attitude towards brand and cognitive loyalty to brand. Next, we present details of the implementation of VIKOR method for ranking different ethical alternatives in Table 4. 
Table 4

The summary of VIKOR method

\begin{tabular}{clcccc}
\hline Row & Alternative & $\tilde{S}$ & $\tilde{R}$ & $\tilde{O}$ & $\mathrm{Q}$ \\
\hline 1 & Standard & $(.42,1.33,3.93)$ & $(.08, .17, .65)$ & $(.44, .65, .82)$ & 0.64 \\
2 & Acceptance of & $(.48,1.47,4.23)$ & $(.094, .19, .67)$ & $(.10, .38, .87)$ & 0.41 \\
3 & On time delivery & $(.49,1.46,4.10)$ & $(.11, .22, .58)$ & $(.44, .69, .79)$ & 0.66 \\
4 & Cheerfulness & $(.39,1.49,4.22)$ & $(.12, .23, .80)$ & $(.45, .76, .96)$ & 0.74 \\
5 & Patience with & $(.54,1.64,4.51)$ & $(.09, .20, .65)$ & $(.29, .40, .89)$ & 0.46 \\
6 & Empathy & $(.38,1.72,3.23)$ & $(.05, .17, .34)$ & $(.33, .69, .72)$ & 0.63 \\
7 & Made promises & $(.41,1.13,4.69)$ & $(.08, .10, .37)$ & $(.05, .18, .44)$ & 0.2 \\
8 & Facilitating & $(.22,1.09,3.90)$ & $(.12, .23, .38)$ & $(.14, .29, .39)$ & 0.28 \\
9 & Welcoming & $(.88,1.92,4.78)$ & $(.32, .53, .90)$ & $(.68, .86, .98)$ & 0.85 \\
10 & Fraud & $(.45,1.67,3.54)$ & $(.09, .27, .66)$ & $(.19, .34, .69)$ & 0.373 \\
11 & Hazard & $(.49,1.76,4.93)$ & $(.18, .25, .88)$ & $(.24, .55, .72)$ & 0.52 \\
12 & Feeling & $(.58,1.77,4.33)$ & $(.09, .18, .62)$ & $(.11, .33, .80)$ & 0.378 \\
13 & Honesty & $(.29,1.06,3.19)$ & $(.12, .32, .68)$ & $(.10, .23, .44)$ & 0.24 \\
14 & Being informative & $(.24,1.09,4.12)$ & $(.15, .23, .56)$ & $(.41, .66, .87)$ & 0.65 \\
\hline
\end{tabular}

According to Table 4, welcoming customer is the most influential factor as an ethical method for attracting customers. In fact, when customers are welcomed, properly, they may feel more comfortable for making an appropriate purchase decision. Having cheerful employees is the second important factor for ethically attracting customer and having loyal customers. On time delivery is the third important factor for ethically attracting customers. People normally expect to receive their orders on timely manner. Being informative is the next important option in our survey, which means customer expect business owners to provide complete information on products and services. Standard and having empathy towards customers are also important criteria for attracting potential customers.

\section{Conclusion}

In this paper, we have presented a multi-criteria decision making techniques for ranking different factors influencing customer loyalty as well as ethical factors for loyal customer retention. The implementation of the proposed method used fuzzy numbers to handle any uncertainty on numbers and we believe this creates an advantage to reach reliable responses. In addition, the proposed study used fuzzy VIKOR to rank 14 ethical factors that could attract customers.

\section{Acknowledgment}

The authors would like to thank the anonymous referees for constructive comments on earlier version of this paper.

\section{References}

Afsharkazemi, M.A., Khodabakhsh, M., \& Motadel, M.R. (2012). Applying fuzzy analytic network process in quality function deployment model. Management Science Letters, 2(4), 1325-1340.

Alvandi, M., Fazli, S., Yazdani, L., \& Aghaee, M. (2012). An Integrated MCDM Method in Ranking BSC Perspectives and key Performance Indicators (KPIs). Management Science Letters, 2(3), 995-1004.

Chen, L. Y., \& Wang, T.-C. (2009). Optimizing partners' choice in IS/IT outsourcing projects: The strategic decision of fuzzy VIKOR. International Journal of Production Economics, 120(1), 233242. 
Chu, M.T., Shyu, J., Tzeng, G.H., \& Khosla, R. (2007). Comparison among three analytic method for knowledge communication group decision analysis. Expert Systems with Applications, 33(4), $1011-1024$.

Fazli, S., \& Jafari, H. (2012). Developing a hybrid multi-criteria model for investment in stock exchange. Management Science Letters, 2(2), 457-468.

Lin, C. T., \& Tsai, M. C. (2009). Development of an expert selection system to choose ideal cities for medical service ventures. Expert Systems with Applications, 36(2), 2266-2274.

Opricovic, S. (1998). Multiple criteria Optimization of Civil Engineering Systems, Faculty of Civil Engineering, Belgrade.

Opricovic, S. (2008). A compromise solution in water resources planning. Water resource management, 23, 1549-1561.

Opricovic, S., \& Tzeng, G.H. (2004). Compromise solution by MCDM method: A comparative analysis of VIKOR and TOPSIS. European Journal of Operational Research, 156 (2), 445-455.

Saaty, T. L. (1996). The analytic network process-decision making with dependence and feedback. Pittsburgh, PA: RWS Publications.

Saaty, T. L. (2004). Decision making - the analytic hierarchy and network processes (AHP/ANP). Journal of systems science and systems engineering, 13(1), 1-35.

Sekitani, K., \& Takahashi, I. (2001). A unified model and analysis for AHP and ANP. Journal of the Operations Research Society of Japan, 44(1), 67-89.

Serkani, E. S., Mardi, M., Najafi, E., Jahanian, K., \& Herat, A. T. (2013). Using AHP and ANP approaches for selecting improvement projects of Iranian Excellence Model in healthcare sector. African Journal of Business Management, 7(23), 2271-2283.

Trajkovic, S., Avakumovic, D., \& Opricovic S. (1997). Multi criteria optimization of an irrigation system. Architecture and Civil Engineering, 1(4), 547 - 552.

Tzeng G.H., Lin C.W., \& Opricovic, S. (2005). Multi criteria analysis alternative fuel buses for public transportation. Energy Policy, 33, 1373-1383.

Ware, N.R., Sing, S.P., \& Banwet, D.K. (2012). Supplier selection problem: A state-of-the-art review. Management Science Letters, 2(5), 1465-1490.

Wu, H.Y., Tzeng, G.H., \& Chen, Y.H. (2009). A fuzzy MCDM approach for evaluating banking performance based on Balanced Scorecard. Expert Systems with Applications, 36(6), 10135-10147.

Yadollahi Farsi, J., Siahkali Moradi, J., Jamali, B. (2012). Which product would be chosen? A fuzzy VIKOR method for evaluation and selection of products in terms of customers' point of view; Case study: Iranian cell phone market. Decision Science Letters, 1(1), 23-32. 